\title{
Cooperation of Mast Cells and Basophils in Allergy
}

Enrico Crivellato ${ }^{1}$ and Domenico Ribatti ${ }^{2 *}$

${ }^{1}$ Department of Experimental and Clinical Medicine, Anatomy Section, University of Udine Medical School, Italy

${ }^{2}$ Department of Basic Medical Sciences, Neurosciences and Sensory Organs, University of Bari Medical School, Italy

\begin{abstract}
Mast cells and basophils are granulated cells, which share similar phenotypic and functional properties. They express complementary and partially overlapping roles in acquired and innate immunity, including both effector and regulatory activities, but they also display important distinctive features as to developmental lineage, mediator content, and function. They cooperate in expanding and/or modulating inflammation as well as in mediating subsequent tissue repair. Mast cells release in the inflammatory scenario a series of potent proangiogenic molecules that stimulate vessel sprouting and new vessel formation. Recent data suggest that basophils may also play a role in inflammation-related angiogenesis, principally but not exclusively through the expression of several forms of VEGF and their receptors. This review focuses on the potential cooperative link between mast cells and basophils in promoting angiogenesis during allergic inflammation. We discuss the multifaceted roles of mast cells and basophils in the inflammatory setting during allergic diseases and whether these cells can be both source and target cells for proangiogenic mediators.
\end{abstract}

Keywords: Mast cells; Basophils; Allergic inflammation; Angiogenesis

\section{Introduction}

Mast cells and basophils represent distinct haematopoietic lineages that can express complementary or overlapping functions in the context of acute and chronic immunoglobulin E (IgE)-associated allergic responses [1,2]. They both contribute to leukocyte recruitment, stromal and tissue cell activation, modulation of immune reactions, tissue remodelling and angiogenesis. Both cell types play a critical role in innate immunity to parasite and bacterial infection [3] and can be activated by bacterial and viral proteins $[4,5]$. Both cells express immunoregulatory functions in IgE-dependent inflammatory reactions $[1,6]$. In addition, they both synthesize and release VEGF, the most potent proangiogenic mediator known so far $[7,8]$. Remarkably, both cell types have the potential to present antigens to $\mathrm{T}$ cells through HLA class I and II molecules. Under certain conditions, indeed, mast cells and basophils can directly activate $\mathrm{T}$ cells by functioning as antigen presenting cells [9]. This review will discuss recent advances in understanding the potential cooperative link between mast cells and basophils, which may promote distinct aspects of immune reactions in the course of allergic inflammation.

\section{General Biology of Mast Cells and Basophils}

Mast cells and basophils were first described by the German pathologist Paul Ehrlich as granulated metachromatic cells $[10,11]$. He coined the term "Mastzellen" which means well-fed cells, because the cytoplasm of these cells was stuffed with granular material. The complex development of their discovery and the subsequent elucidation of their properties revealed that these cells share similar phenotypic and functional features but differ in important aspects of natural history, mediator content, and function. The main histochemical difference between mast cells and basophils is their distinct metachromatic staining, which primarily reflects their different content of proteoglycans of cytoplasmic granules. For instance, chondroitin sulfates are present both in basophils and mast cells whereas heparin is detectable in mast cells exclusively [12]. Mast cells and basophils have different developmental patterns. Mast cells are tissue-resident cells, which arise in the bone marrow from CD34 haematopoietic stem cells [13]. They migrate into almost all of the major organs as immature committed progenitors, whose maturation is influenced by stem cell factor (SCF) binding to the receptor c-kit and by other cytokines such as interleukin (IL)-3, IL-4, IL-9, and IL-10 [14]. Mature mast cells can be very longlived and can retain their ability to proliferate under certain conditions. They are found in the skin and in all mucosal tissues at homeostasis, and numbers are elevated in asthmatics lungs and gastrointestinal tract of inflammatory bowel disease. In contrast to mast cells, basophils are circulating granulocytes that typically mature in the bone marrow, circulate in the blood as mature cells, and can be recruited into sites of immunological or inflammatory responses but are not found in normal tissues [15]. They also arise from $\mathrm{CD} 34^{+}$haematopoietic progenitors and, under physiological conditions, have a short life-span of several days. Unlike mast cells, they do not proliferate once they mature. As basophils lack c-kit, they do not respond to SCF. By contrast, their differentiation is crucially driven by IL-3, which promotes the production and survival of human basophils in vitro and can induce basophilia in vivo [16]

\section{Mast Cell and Basophil Activation and Mediator Release}

Mast cells and basophils release secretory products by either anaphylactic degranulation ("compound exocytosis") or piecemeal degranulation, a slow particulate and possibly selective mode of cell secretion mediated by vesicle transport of granule-stored material [12]. Mediators are either preformed or granule-associated or are synthesized de novo. Both cells are able to release potent inflammatory mediators, such as histamine, proteases, chemotactic factors, cytokines and metabolites of arachidonic acid that act on the vasculature, smooth muscle, connective tissue, mucous glands and inflammatory cells. Major

*Corresponding author: Domenico Ribatti, Department of Basic Medical Sciences, Neurosciences and Sensory Organs, University of Bari Medical School Piazza G. Cesare, 11, Policlinico, 70124 Bari, Italy, Tel: 39-080-5478326; Fax: 39080-5478310; E-mail: domenico.ribatti@uniba.it

Received March 22, 2013; Accepted May 22, 2013; Published May 29, 2013

Citation: Crivellato E, Ribatti D (2013) Cooperation of Mast Cells and Basophils in Allergy. J Allergy Ther 4: 135. doi:10.4172/2155-6121.1000135

Copyright: (C) 2013 Crivellato E, et al. This is an open-access article distributed under the terms of the Creative Commons Attribution License, which permits unrestricted use, distribution, and reproduction in any medium, provided the original author and source are credited. 
mediators stored preformed in mast cell granules are histamine, heparin, serine proteases such as tryptase and chymase, cathepsin G, peroxidase, many acidic hydrolases, carboxypeptidases and antimicrobial peptides such as cathelicidins [17]. Basophil granules contain less amount of histamine, lack heparin but contain proteoglycans like chondroitin sulphates and Charcot-Leyden crystal protein. In some allergic settings, circulating basophils may contain tryptase, chymase, carboxypeptidase $\mathrm{A}$, and express the c-kit receptor-that normally lacks on the basophils surface-which suggests that these cells may modulate their phenotype [18]. Newly generated mediators consist of arachidonic acid metabolites, principally cysteinyl leukotrienes (LTB4 and LTC4), prostaglandins (PGE2 and PGD2), and platelet-activating factor (PAF) and cytokines such as tumor necrosis factor (TNF- $\alpha, \beta)$, transforming growth factor (TGF)- $\beta$, fibroblast growth factor (FGF)-2, vascular endothelial growth factor (VEGF), granulocyte macrophage-colony stimulating factor (GM-CSF), nerve growth factor (NGF), platelet-derived growth factor (PDGF), interferon (IFN)- $\alpha,-\beta$ and $-\gamma$, and IL-4, IL-5, IL-6, IL- $1 \beta$ and IL-13. By contrast, LTC4 and PAF are the only identified lipid mediators released by basophils [19]. All these mediators can exert profound effects on inflammation, immunity, haematopoiesis, tissue remodelling and other biological functions. Human and mouse mast cells secrete several C-C and CXC chemokines, including monocyte chemotactic protein (MCP)-1 (CCL-2) and macrophage inflammatory protein (MIP)-1a (CCL-3). IL-8 (CXCL-8) has chemokine functions as well. Basophils are a major source of pro-allergic cytokines, such as IL-4, and have been shown to be responsible for $72 \%$ of IL- 4 protein-positive cells in the bronchial mucosa during allergen-induced asmathic reactions [20]. These cells also comprise the dominant IL-4-producing cell in the bronchoalveolar lavage fluid following segmental lung challenge [21]. Basophils also secrete VEGF, IL-6 and IL-13 [19].

\section{Mast Cell and Basophil in Allergy}

Both mast cells and basophils express the tetrameric $\alpha \beta \gamma_{2}$ form of the high-affinity receptor FceRI for IgE on their surface and both kinds of cells are crucial effectors in T helper 2 (Th2)-cell-dependent, IgEassociated allergic disorders and immune responses to parasites [2225]. IgE play a crucial role in the immediate hypersensitivity response but other IgE-independent mechanisms, such as $\mathrm{G}$ protein-coupled receptor and Toll-like receptor activation processes may intervene $[26,27]$. Activated mast cells and basophils release Th2 cytokines (IL-4, IL-5, IL-9 and IL-13) that polarize the immune reaction, and produce various bioactive chemical mediators, such as histamine and lipid metabolites, that provide vasoactive, chemotactic and immunoregulatory functions $[28,29]$.

In addition to their roles in classic acute IgE-associated immediate hypersensitivity responses, several lines of evidence indicate that mast cells and basophils can also contribute to late-phase and chronic allergic reactions [30-32]. A key molecule in this context is IL-33. IL33 is a member of the IL-1 cytokine family, which is preferentially and constitutively expressed in epithelial cells, and it is especially localized in the cell nucleus. The nuclear IL-33 is released by necrotic cells after tissue injury and subsequently provokes local inflammation. This activation causes the cells to produce Th2 cytokines, which contribute to the development of allergy. The IL-33 receptor (IL-33R) is a heterodimer comprised of IL-1RL1 and IL-1 receptor accessory protein (IL-1RAcP). Genetic polymorphism of IL-33 and IL-1RL1 is suspected of causing susceptibility to development of asthma in certain patients. Genetic polymorphism of IL-1RL1 has also been identified in patients with atopic dermatitis, and expression of IL-33 is increased in inflamed skin from these patients, suggesting involvement of IL-33 in the development of atopic dermatitis. Human peripheral blood or cord blood progenitor cell-derived MCs and mouse peritoneal and bone marrow-derived cultured MCs constitutively express IL-1 RL1 that induces expression of mouse MC protease-6, prolong survival and promote adhesion of naïve human and murine MCs without inducing degranulation in response to IL-33. IL-33 can enhance IgE/Ag-, monomeric IgE-, C5a-, SCF- and NGF-mediated cytokine production in human and mouse MCs. In human and/or mouse naïve basophils that constitutively express IL-1RL1, IL-33 can induce production of such cytokines and chemokines as IL-4, IL-5, IL-6, IL-8, IL-13, GMCSF, CCL2, CCL3 and CCL4 and cell adhesion by promoting CD11b expression, without inducing degranulation or migration. IL-33 enhances IgE-mediated degranulation and migration as well as IgEand IL-3-mediated cytokine and chemokine production in human and mouse basophils. IL-33 also enhances the receptor for leptin on human basophils, suggesting that IL-33 may be involved in metabolic abnormalities associated with inflammation via basophil activation. In ragweed pollen-induced allergic rhinitis, IL-33 enhances release of histamine and chemoattractant factors for eosinophils and basophils by mast cells and basophils, contributing to local inflammation in the early and late phases of diseases. Another proinflammatory cytokine recently found to be involved in allergy is IL-18. IL-18 plays an important role in Th1/Tc1 polarization and promoting the production of Th2 cytokines (e.g., IL-4, IL-5, IL-9, and IL-13) by T cells, NK cells, basophils, and mast cells. IL-18 can act as a cofactor for Th2 cell development and IgE production, and also plays an important role in the differentiation of Th17 cells. IL-18 is a key player in the pathogenesis of inflammatory diseases such as atopic dermatitis. Furthermore, many lines of evidence suggest that IL-18 plays a key role in the pathogenesis of pulmonary inflammatory diseases, including bronchial asthma and chronic obstructive pulmonary disease.

In asthmatics, the number of the MCs increases at sites of inflammation. Activation of MCs is detected by higher spontaneous release of histamine by mast cells obtained from the bronchoalveolar lavage (BAL) of asthmatics and by elevated levels of tryptase and PGD2 in BAL. MCs have been shown to change their degranulation pattern from acute to chronic allergic responses [33]. Many clinical symptoms of IgE-dependent late-phase reactions, both in the respiratory tract, gastrostrointestinal tract and the skin, reflect the actions of the leukocytes recruited to these sites by MCs and basophils through release of TNF- $\alpha$, IL-6, IL-8, neutral proteases, as well as histamine and lipid mediators [34]. Recent experimental work on mice has demonstrated that there is a sequential engagement of FceRI on MCs and basophil histamine $\mathrm{H}(4)$ receptor and FceRI in allergic rhinitis. Results demonstrate the development of allergic rhinitis proceeded in two distinct stages: histamine release from FceRI-activated mast cells, followed by histamine-mediated recruitment of $\mathrm{H}(4) \mathrm{R}$-expressing basophils to the nasal cavity and activation through FceRI [35]. Certain MC cytokines, such as TNF- $\alpha$, VEGF, FGF- 2 and TGF- $\beta$, contribute to chronic allergic inflammation through effects on fibroblasts, vascular endothelial cells, and other cells resident at the sites of these reactions. Persistent chronic allergic inflammation can result in remodelling of the affected tissues and these structural changes are often associated with activation of the angiogenic process.

\section{Inflammation, Angiogenesis and Tissue Remodelling}

Airway tissues from patients with asthma characteristically show blood vessel proliferation in the mucosa and submucosa. The major structural and functional changes of the airway microcirculation include the proliferation of new vessels, increased vascular area of the 
medium and small airways, increased blood flow and microvascular permeability, and edema formation in the airway wall [36,37]. Inflammation and angiogenesis are driven by numerous factors among which cytokines of the CXC family provide a pivotal role [38]. IL-33 can induce production of chemokines such as CCL2, CCL3 and CCL4 by human and mouse naïve basophils that constitutively express IL1RL1. Thus, not only CXC chemokines are responsible for leukocyte recruitment to inflamed tissues but they also regulate the inflammatory reaction leading to angiogenesis, tissue repair and new tissue generation [39-42].

MCs and basophils participate in the same inflammatory scenario along with other blood-born and tissue-resident cells in the course of different allergic conditions [43]. These cells cooperate in expanding and/or modulating inflammation as well as in mediating tissue remodelling and angiogenesis [44]. Many mediators and receptors are involved in such paracrine and autocrine networks. MCs and basophils are endowed with a wide set of chemokine receptors. Basophils constitutively express CCR1, CCR2, CCR3, CXCR1, CXCR3, and CXCR4 [6]. CCR3 is highly expressed on human basophils and can be activated by eotaxin (CCL11), RANTES (CCL5), MCP-3 (CCL7) and MCP-4 (CCL13) [45]. In contrast to human basophils, mouse basophils do not express CCR3. Interestingly, CCR3 is also expressed by about $25 \%$ of lung mast cells in subjects with bronchial asthma [46]. Upon IgE overproduction, mouse basophils release CCL22, which is a potent chemoattractant for Th2 cells and has been implicated in Th2predominant allergic inflammation [47].

MCs and basophils are a major source of several angiogenic factors among which the VEGF, the most potent proangiogenic mediator $[8,7]$. VEGF may be released by MCs by exocytosis or in the absence of degranulation. Selective release of VEGF by human MCs is mediated by $\mathrm{CRH}$ or by activation of the EP(2) receptor by PGE2 $[48,49]$. VEGF is also produced by human basophils [8], which express the tyrosine kinase VEGF-A receptor VEGFR-2/KDR. VEGF-A also functions as basophil chemoattractant providing a novel autocrine loop for basophils self-recruitment. Both MCs and basophils release histamine, which displays angiogenic activity in several in vitro and in vivo settings [50]. MCs synthesize and release other potent angiogenic cytokines, such as FGF-2, the serine proteases tryptase and chymase, IL-8, TGF- $\beta$, TNF- $\alpha$ and NGF. In addition, both MCs and basophils express the high affinity urokinase plasminogen activator receptor (UPAR) for the urokinase plasminogen activator (uPA) [51,52]. uPA is a potent chemoattractant for both kind of cells and, remarkably, uPA and uPAR are involved in tissue remodelling and vessel sprouting. MCs from human uterine leiomyomas contain leptin, a 167-amino-acid residue peptide mainly secreted by adipocytes which, besides its involvement in obesity development, expresses angiogenic activity [53]. In addition, human skin, lung and synovial MCs contain matrix metalloproteinase (MMP)-9, which degrade and remodel the extracellular matrix (ECM) thus releasing ECM-bound angiogenic factors [54].

\section{Concluding Remarks}

MCs and basophils are effector cells in allergic conditions such as bronchial asthma. They can also cooperate in the process of tissue remodelling associated with allergic inflammation. These cells produce numerous mediators and express surface receptors that provide the basis for complex paracrine and autocrine cross-talking networks. They are both source and target cells for proinflammatory and proangiogenic mediators. Understanding the increasingly complexity of the interaction between basophils and MCs as well as between these cells and the other tissue resident and inflammatory cells in the allergic scenario would mean increase our capacity to modify and control dangerous aspects of inflammation.

\section{Acknowledgement}

The authors do not declare any conflict of interest. This study has been supported by MIUR local funds to the Department of Medical and Morphological Research, Anatomy Section, University of Udine.

\section{References}

1. Gribaldeston MA, Metz M, Yu M, Tsai M, Galli SJ (2006) Effector and potential immunoregulatory roles of mast cells in IgE-associated acquired immune responses. Curr Opin Immunol 18: 751-760.

2. Galli SJ, Grimbaldeston M, Tsai M (2008) Immunomodulatory mast cells: negative, as well as positive, regulators of immunity. Nat Rev Immunol 8: 478486.

3. Metz M, Siebenhaar F, Maurer M (2008) Mast cell functions in the innate skin immune system. Immunobiology 213: 251-260.

4. Patella V, Giuliano A, Bouvet JP, Marone G (1998) Endogenous superallergen protein $\mathrm{Fv}$ induces IL-4 secretion from human Fc epsilon $\mathrm{RI}+$ cells through interaction with the VH3 region of IgE. J Immunol 161: 5647-5655.

5. Patella V, Florio G, Petraroli A, Marone G (2000) HIV-1 gp120 induces IL-4 and IL-13 release from human Fc epsilon $\mathrm{RI}+$ cells through interaction with the $\mathrm{VH} 3$ region of IgE. J Immunol 164: 589-595.

6. Gibbs BF (2005) Human basophils as effectors and immunomodulators of allergic inflammation and innate immunity. Clin Exp Med 5: 43-49.

7. Dvorak AM (2005) Mast cell-derived mediators of enhanced microvascular permeability, vascular permeability factor/vascular endothelial growth factor, histamine, and serotonin, cause leakage of macromolecules through a new endothelial cell permeability organelle, the vesiculo-vacuolar organelle. Chem Immunol Allergy 85: 185-204

8. de Paulis A, Prevete N, Fiorentino I, Rossi FW, Staibano S, et al. (2006) Expression and functions of the vascular endothelial growth factors and their receptors in human basophils. J Immunol 177: 7322-7331.

9. Frandji P, Tkaczyk C, Oskeritzian C, David B, Desaymard C, et al. (1996) Exogenous and endogenous antigens are differentially presented by mast cells to CD4+ T lymphocytes. Eur J Immunol 26: 2517-2528.

10. Ribatti D, Crivellato E (2009) The controversial role of mast cells in tumor growth. Int Rev Cell Mol Biol 275: 89-131.

11. Ehrlich P (1879) Beiträge zur Kenntnis der granulierten Bindgewebszellen und der eosinophilen Leukocyten. Arch Anat Physiol 3: 166-169.

12. Dvorak AM (2005) Ultrastructural studies of human basophils and mast cells. J Histochem Cytochem 53: 1043-1070.

13. Okayama Y, Kawakami T (2006) Development, migration, and survival of mast cells. Immunol Res 34: 97-115.

14. Ashman LK (1999) The biology of stem cell factor and its receptor C-kit. Int Biochem Cell Biol 31: 1037-1051.

15. Arock M, Schneider E, Boissan M, Tricottet V, Dy M (2002) Differentiation of human basophils: an overview of recent advances and pending questions. $J$ Leukoc Biol 71: 557-564

16. Valent P, Schmidt G, Besemer J, Mayer P, Zenke G, et al. (1989) Interleukin-3 is a differentiation factor for human basophils. Blood 73: 1763-1769.

17. Galli SJ, Kalesnikoff J, Grimbaldeston MA, Piliponsky AM, Williams CM, et al. (2005) Mast cells as "tunable" effector and immunoregulatory cells: recent advances. Annu Rev Immunol 23: 749-786.

18. Li L, Li Y, Reddel SW, Cherrian M, Friend DS, Stevens RL, Krilis SA( 1998) Identification of basophilic cells that express mast cell granule proteases in the peripheral blood of asthma, allergy and drug-reactive patients. J Immunol 161: 5079-5086.

19. Karasuyama H, Mukai K, Tsujimura Y, Obata K (2009) Newly discovered roles for basophils: a neglected minority gains new respect. Nat Rev Immunol 9 . 9-13. 
20. Nouri-Aria KT, Irani AM, Jacobson MR, O'brien F, Varga EM, et al. (2001) Basophil recruitment and IL-4 production during human allergen-induced late asthma. J Allergy Clin Immunol 108: 205-211.

21. Schroeder JT, Lichtenstein LM, Roche EM, Xiao H, Liu MC (2001) IL-4 production by human basophils found in the lung following segmental allergen challenge. J Allergy Clin Immunol 107: 265-271.

22. Sullivan BM, Locksley RM (2009) Basophils: a nonredundant contributor to host immunity. Immunity 30: 12-20.

23. Gould HJ, Sutton BJ, Beavil AJ, Beavil RL, McCloskey N, et al. (2003) The biology of IGE and the basis of allergic disease. Annu Rev Immunol 21: 579628.

24. Prussin C, Metcalfe DD (2003) 4. IgE, mast cells, basophils, and eosinophils. J Allergy Clin Immunol 111: S486-494.

25. Min B, Prout M, Hu-Li J, Zhu J, Jankovic D, et al. (2004) Basophils produce IL-4 and accumulate in tissues after infection with a Th2-inducing parasite. J Exp Med 200: 507-517.

26. Marshall JS, McCurdy JD, Olynych T (2003) Toll-like receptor-mediated activation of mast cells: implications for allergic disease? Int Arch Allergy Immunol 132: 87-97.

27. Vines CM, Prossnitz ER (2004) Mechanisms of G protein-coupled receptormediated degranulation. FEMS Microbiol Lett 236: 1-6.

28. Schroeder JT, MacGlashan DW Jr, Lichtenstein LM (2001) Human basophils: mediator release and cytokine production. Adv Immunol 77: 93-122.

29. Min B, Paul WE (2008) Basophils and type 2 immunity. Curr Opin Hematol 15: 59-63.

30. Galli SJ, Tsai M, Piliponsky AM (2008) The development of allergic inflammation. Nature 454: 445-454

31. Holgate ST (2002) Airway inflammation and remodeling in asthma: current concepts. Mol Biotechnol 22: 179-189.

32. Mukai K, Matsuoka K, Taya C, Suzuki H, Yokozeki H, et al. (2005) Basophils play a critical role in the development of IgE-mediated chronic allergic inflammation independently of T cells and mast cells. Immunity 23: 191-202.

33. Theoharides TC, Kempuraj D, Tagen M, Conti P, Kalogeromitros D (2007) Differential release of mast cell mediators and the pathogenesis of inflammation. Immunol Rev 217: 65-78.

34. Puxeddu I, Ribatti D, Crivellato E, Levi-Schaffer F (2005) Mast cells and eosinophils: a novel link between inflammation and angiogenesis in allergic diseases. J Allergy Clin Immunol 116: 531-536.

35. Shiraishi Y, Jia Y, Domenico J, Joetham A, Karasuyama H, et al. (2013) Sequential engagement of Fcl̂ $\mu$ RI on Mast Cells and Basophil Histamine $\mathrm{H}(4)$ Receptor and Fcî $\mu R I$ in Allergic Rhinitis. J Immunol 190: 539-548.

36. McDonald DM (2001) Angiogenesis and remodeling of airway vasculature in chronic inflammation. Am J Respir Crit Care Med 164: S39-45.

37. Wilson $\mathrm{J}(2000)$ The bronchial microcirculation in asthma. Clin Exp Allergy 30 Suppl 1: 51-53.

38. Romagnani P, Lasagni L, Annunziato F, Serio M, Romagnani S (2004) CXC chemokines: the regulatory link between inflammation and angiogenesis. Trends Immunol 25: 201-209.

39. Mehrad B, Keane MP, Strieter RM (2007) Chemokines as mediators of angiogenesis. Thromb Haemost 97: 755-762.

40. Zaja-Milatovic S, Richmond A (2008) CXC chemokines and their receptors: a case for a significant biological role in cutaneous wound healing. Histol Histopathol 23: 1399-1407.

41. Keeley EC, Mehrad B, Strieter RM (2008) Chemokines as mediators of neovascularization. Arterioscler Thromb Vasc Biol 28: 1928-1936.
42. Salcedo R, Oppenheim JJ (2003) Role of chemokines in angiogenesis: CXCL12/SDF-1 and CXCR4 interaction, a key regulator of endothelial cell responses. Microcirculation 10: 359-370.

43. Marone G, Triggiani M, Genovese A, De Paulis A (2005) Role of human mast cells and basophils in bronchial asthma. Adv Immunol 88: 97-160.

44. Marone G, Triggiani M, de Paulis A (2005) Mast cells and basophils: friends as well as foes in bronchial asthma? Trends Immunol 26: 25-31.

45. Gibbs BF (2005) Human basophils as effectors and immunomodulators of allergic inflammation and innate immunity. Clin Exp Med 5: 43-49.

46. Brightling CE, Kaur D, Berger P, Morgan AJ, Wardlaw AJ, et al. (2005) Differential expression of CCR3 and CXCR3 by human lung and bone marrowderived mast cells: implications for tissue mast cell migration. J Leukoc Bio 77: 759-766.

47. Watanabe M, Satoh T, Yamamoto Y, Kanai Y, Karasuyama H, et al. (2008) Overproduction of $\mathrm{IgE}$ induces macrophage-derived chemokine (CCL22) secretion from basophils. J Immunol 181: 5653-5659.

48. Abdel-Majid RM, Marshall JS (2004) Prostaglandin E2 induces degranulationindependent production of vascular endothelial growth factor by human mast cells. J Immunol 172: 1227-1236.

49. Cao L, Curtis CL, Theoharides TC (2006) Corticotropin-releasing hormone induces vascular endothelial growth factor release from human mast cells via the cAMP/protein kinase A/p38 mitogen activate protein kinase pathway. Mol Pharmacol 69: 998-1006.

50. Norrby K (2002) Mast cells and angiogenesis. APMIS 110: 355-371.

51. Sillaber C, Baghestanian M, Hofbauer R, Virgolini I, Bankl HC, et al. (1997) Molecular and functional characterization of the urokinase receptor on human mast cells. J Biol Chem 272: 7824-7832.

52. de Paulis A, Montuori N, Prevete N, Fiorentino I, Rossi FW, et al. (2004) Urokinase induces basophil chemotaxis through a urokinase receptor epitope that is an endogenous ligand for formyl peptide receptor-like 1 and -like 2 . J Immunol 173: 7734-7743.

53. Ribatti D, Belloni AS, Nico B, Salà G, Longo V, et al. (2007) Tryptase- and leptin-positive mast cells correlate with vascular density in uterine leiomyomas. Am J Obstet Gynecol 196: 470.

54. Kanbe N, Tanaka A, Kanbe M, Itakura A, Kurosawa M, et al. (1999) Human mast cells produce matrix metalloproteinase 9. Eur J Immunol 29: 2645-2649. 